Article

\title{
Rapid Games Designing; Constructing a Dynamic Metaphor to Explore Complex Systems and Abstract Concepts
}

\author{
Bruce A Lankford ${ }^{1, *}$ and Joanne Craven ${ }^{2}$ (1) \\ 1 School of International Development, University of East Anglia, Norwich NR4 7TJ, UK \\ 2 Food Systems Transformation Programme, Environmental Change Institute, University of Oxford, \\ Oxford OX1 3QY, UK; joanne@joannecraven.co.uk \\ * Correspondence: b.lankford@uea.ac.uk
}

Received: 15 July 2020; Accepted: 31 August 2020; Published: 3 September 2020

check for updates

\begin{abstract}
Initiated by a research project examining agricultural and water resilience in South Africa and tested in workshops on a range of topics, we reflect on our application of a half-to-one day "games designing" format for constructing dynamic metaphors for complex systems and related concepts (e.g., the resilience or sustainability of a catchment/agricultural marketing system). While this short format gives rich and detailed games that potentially could be played in an extended version of the workshop, we did not go ahead with this step. Instead, we devoted the limited time available to supporting participants in designing, comparing and discussing their games and to exploring the concepts and meanings of a given complex system, even if the latter was initially deemed by participants to be abstract and "academic". Our abridged term for short-format games designing is "rapid games designing" (RGD). Key benefits to participating individuals, the whole group and workshop organizers include (a) the highly productive and creative use of limited time; (b) an inclusive group exercise that draws everyone into the process; (c) rich discussion of pluralist viewpoints through the comparison of the remarkable variety of games generated, including their differences in purpose, players and rules; and (d) observations on how the games construct a dynamic metaphor for the system and its properties, leading to deeper insights and knowledge building regarding system concepts and components. Here, we use two case studies in South Africa to explore what value RGD provides and how it does so, and then we briefly compare it to other similar methods. We also provide practical guidance for facilitating RGD workshops. In conclusion, we argue this format offers an option for the ongoing evolution of games about complex human, natural and socio-ecological systems and that it generates considerable creativity, learning, discussion and insights amongst all participants.
\end{abstract}

Keywords: board games; games designing; knowledge creation; metaphor; stakeholder participation; serious gaming; serious play

\section{Introduction}

The use of different types of games for exploring the sustainability of social-ecological systems and related concepts has seen an increase in the last 20 years [1-3]. This is perhaps no surprise, as games generate a number of benefits for those involved in their design, use and review. These include an ability to qualitatively and quantitatively research how resource/system stakeholders perceive and interact with their associated systems; increased participation levels; new, more coherent and collective understandings of the component factors, behaviors and dynamics of system sustainability; and increased engagement and trust from resource managers and regulators. While these benefits do 
not always apply equally to all types of games, as an enriching participatory, deliberative and often empowering tool, games have wide-ranging benefits and utility $[4,5]$.

It is claimed that to achieve organizational change on the scale that is required to address global sustainability challenges, we need to enable the expression of heterogeneous perspectives and their integration into shared understandings of complex social and ecological systems [6-9]. This is not easily achieved, and the stimuli and background to this paper and its "rapid" approach to games design comes from a key problematic derived from the two authors' experience using games to achieve this. This problematic can be distilled into one question: what is a highly effective format for quickly engaging actors in effective deliberations to understand the systems they are associated with? In answering this question, we found ourselves gravitating towards the design of games rather than the playing of games [10]. Five workshops, held from 2017 to 2019 and covering different topics, provided experience to hone our approach, now described in this paper and its appendix. We term this approach "rapid games designing" (RGD).

Typically, when discussing game formats used for increasing the understanding of systems and their behaviors, the literature refers to the playing of a game [2,11]. Although not exclusively, these games tend to be designed by people with an observational role in the system (such as researchers or trainers) rather than the players themselves, who are "system actors" such as resource users, employees, managers and decision-makers. Input from system actors can be incorporated, but the design and playing process tends to be mediated by the person or team designing the game. Even games that are "codesigned" will have considerable input from the facilitators [12]. Thus in our view, in game playing, stakeholders closely connected to a given system are given either a predesigned game or a set of structures and rules that result in one type of game being "codesigned" and formulated. By contrast, our game designing approach entails a free and open-ended structure.

Furthermore, RGD comes from the idea that the game design process is valuable in itself. Therefore, it is more useful for system actors as participants to go through the design process than it is for experienced formal game designers because the former are the "target audience", both for expressing their understanding of the system and being the people able to effect change. Thus, because these system actors are not shackled to an understanding of the system chosen by the designer, we think RGD can be as valuable as or more so than playing a predesigned game in some contexts.

Additionally, rapid games designing stems from the authors' concerns that when arranging and devising games workshops, several logistical and pedagogic constraints commonly arise. These include (1) how to fit a games session within contemporary workshop schedules, often not going over more than a day; (2) how to run a workshop that can accommodate approximately 10 to 50 people; (3) how to accommodate different personalities and expertise levels to maximize inclusion, learning and discussion while minimizing dead time or frustrations that hamper learning; and (4) how to travel with games materials that are portable.

In brief, the RGD format uses a half- to one-day workshop for 10-50 people whereby three to six groups of three to eight participants are led through the process of designing prototype tabletop games representing a dynamic and complex human/socio-ecological system. The workshop begins with guided exercises (or "baby steps") to bring participants to a point where they are comfortable building game prototypes using the game materials provided. They then have 60-90 min to create the outline of a game that they feel recreates the complex system —or an aspect of it. This results in a number of games representing different group perspectives on the system, the comparison of which provides rich material for discussion in the last part of the workshop, where participants consider similarities and differences between the games to create a whole-workshop vision of the system.

Interpreting and getting value from the games by workshop participants happens in five stages (see also Appendix A). Stage 1 occurs at the start of the workshop to introduce the participants to game designing. Stage 2 comprises $60-90 \mathrm{~min}$ of game designing, with one game produced by each group. Stage 3 takes place in the form of questions and answers when each group presents their game to the rest of the participants. This is where much additional explanation and feedback 
happens, and it is important that it is facilitated well. Furthermore, this uncovers the design process, whether disagreements arose or whether gaps and omissions were planned or not (for example, comments such as "ah, we didn't think of that" or "we don't think things work like that" were common during the Q\&A stage). Moreover, Stage 3 aims to clarify that each game is one perspective on the real world, preparing the ground towards Stage 4: a plenary discussion that integrates these multiple perspectives into a shared perspective. Stage 4 asks all workshop participants to collectively reflect on the whole day thus far to provide insights on the status of their system or knowledge of their system. Stage 5, after the workshop(s), is an opportunity for the workshop facilitators to more deeply analyze the day and its outcomes. Accordingly, a more formal analysis of the actors, resources, decisions and interactions can be done for each game, group of games and group of workshops.

Rapid game designing is a mental and physical exercise that in turn creates a "game outline" that acts as a mental image and physical model of, or metaphor for, a complex socio-ecological system (e.g., a river catchment, food system or rural-urban linkage). However, there is a view that these systems and their components and qualities (such as their governance or resilience) are seen as abstractions or metaphors for "reality" $[13,14]$. This means games are not only trying to capture "the geography of a catchment" or "the connections of a food system"; instead, we end up with games interpreting abstract qualities and intentions such as catchment governance, its resilience or its behavior under technological change. In other words, the game designing (a metaphor) is capturing a system abstraction (a metaphor).

Moreover, this group-based exercise results in mental images of the dynamics of the complex system animated by movable physical games materials and negotiated aims and rules. We therefore believe that, using "games designing", groups are able to construct a dynamic metaphor together integrating various perspectives and furthermore that they can experience these renditions of the system without having to move to a stage of "game playing". The exercise involves discussion and selective choices over how to reify a system's objectives, elements, processes and boundaries into a game. Therefore, the designed game, with its roles, components, mechanics, interactions and rules, is "dynamic" because (1) it is built from different perspectives held within the group(s), (2) it is materially created as a moving/movable physical model (see photos in Appendix A), (3) it lives in the participant-designers' imaginations as a changing/changeable mental model (e.g., incorporating the tension between possible winners and losers) and (4) it brings to the foreground discussions on why the complex system is seen in these ways (e.g., why it creates winners and losers). To summarize, we believe the approach of "games designing" constructs a dynamic metaphor similarly to how "game playing" uses metaphors for complex systems [9,15], which help unpack abstractions [8].

In this paper, we start by placing RGD within the literature, followed by reporting on two case study workshops from South Africa, detailing both the processual outcomes of the workshops and the characteristics of the games designed. We then go on to use this experience to explore three discussion questions, namely the following:

1. What value does RGD provide to workshop participants and organizers?

2. How does RGD work and function to provide this value?

3. How does RGD compare to similar methods, and for which applications is it particularly valuable?

Via these three discussions, we conclude that our approach is novel and highly effective in getting participants to think about complex, perspectival, spatially distributed and often abstract systems and their associated problems. In Appendix A, we describe how RGD is delivered in a workshop setting and include photographs of some of the workshops already held.

\section{Literature Review}

Our literature review is guided by three questions. First, what games-based knowledge building field does RGD fit within; second, how do we "place" our RGD in the evolving genealogy of resource and system games; and third, to what extent is RGD a novel format? 


\subsection{What Knowledge-Building Field Does RGD Fit within?}

We believe rapid games designing fits within the kinds of cognitive knowledge building seen with other games and experiential learning approaches. Accordingly, research has confirmed the importance of shared visions, exchanges of mental models and systems thinking for learning organizations $[6,7]$ and also the innovative potential of heterogeneity in perspectives on a system $[16,17]$. Creating this shared understanding from heterogeneous perspectives is challenging, but methods involving games have been successfully used to achieve it [18-20]. We contend that rendering a complex system into a metaphor of designing a game increases understanding of it and is therefore a useful tool for exploring social-ecological systems [11,15]. In particular, a key strength of the RGD format with respect to knowledge building is that different groups in the workshop create individual unique "games" in response to the system and questions being set. This allows for a shared discussion comparing all the groups' games, resulting in a much broader overview of the mental models of the complex system. In summary, the cognitive richness of RGD arises because workshop participants (as a whole group) are asked to consider a plurality of designs and models; they do not design or play one predesigned game representing a single mental model.

\subsection{Where Does RGD Fit in the Literature?}

Although our RGD approach is unique, it can be considered in relation to the games/gaming genealogy in two ways. Firstly, in their review of digital games in education, Kafai and Burke [21] divided game-based methods into instructionist methods (where the trainer creates a game the players play) and constructionist methods (where students design the game, and this comprises the learning activity). This distinction was also discussed by Edmonds and Smith [22]. We see RGD sitting at the constructionist end of this instructionist-constructionist spectrum of game-based participatory methods and as a case where the playing component falls away completely to make space for designing and discussions.

Secondly, we conceptualize RGD as a game-based version of the constructionist method of "serious play" or "rapid prototyping", whereby participants are given base materials (paper, cardboard, Lego blocks, etc.) and asked to use them to create and manipulate representations of the system under analysis. These approaches have been used with impressive success in educational, design and corporate strategy contexts [23]. The strengths of the methods are believed to lie in their ability to make participants see a system from new perspectives and to generate a shared perspective through group work [24-30]. RGD is a particular case where the materials used are tabletop game components.

\subsection{How New Is "Rapid Games Designing"?}

By searching the literature on games for engaging with resources and systems, we have not been able to find a format that exactly matches our approach to RGD. We employed a number of search terms to ascertain whether our format was already being used (Box 1). RGD appears to fit within a large field of games-based methods that includes "serious play" and "rapid prototyping", role-playing games, tabletop games and codesign. Free game design as an activity has been used for teaching complex concepts to high school and university students [31-33]. In the field of social-ecological systems, D'Aquino et al. [34] used a scaffolded game design approach for multilevel participatory design of land use policies, but here, participants had limited scope to rethink the structure of the game created by the researchers. However, there were no cases where the free design of games was used to help groups understand and explore complex social-ecological systems. Therefore, we contend that the RGD format is novel.

We should qualify this claim by accepting that individual parts of our format are not new and have their origins in prior work. For example, as seen in Appendix A, our distinction of the "game world" and "real world" draws from learning mechanics/game mechanics [35] and triadic game design's "reality, meaning and play" [1] and are seen in the computer gaming literature [36]. 
Box 1. Search terms for a rapid literature review on games design.

- $\quad$ The search terms used (in various combinations) were as follows:

- [design/making/self-designed/self-made/co-design*/student-designed/student-made/participantdesigned/participant-made]

- $\quad$ [games/board games/card games/serious games]

- [serious play/creative visualization/prototype*/lego]

- [facilitation/creative facilitation/workshop/social learning/scenario*/participation/engagement/communication /participatory development communication]

\section{Results}

Here, we assess the RGD format delivered in a workshop setting (using the outcomes of Stages 2-4) and a selection of the games designed (using the outcome of Stage 5). These two assessments provide the basis for our following discussion section, where we reflect more deeply on these results to answer the three discussion questions posed. From mid-2017 to December 2019, the RGD format has been used five times, twice in South Africa and three times in the UK. We report on some of these experiences, concentrating mainly on the two workshops in South Africa held in Tzaneen (Limpopo province) and in Stellenbosch (Western Cape) with the aim of enabling participants to explore the topic of catchment and agricultural resilience in the face of water scarcity and drought. The Tzaneen workshop was attended by 22 delegates representing commercial and emerging farmers, industry associations, government agencies and the project team. The Stellenbosch workshop was attended by approximately 90 delegates representing commercial growers, pack-houses, agronomists, industry associations, buyers, government agencies and the project team. Photographs in Appendix A capture some games outputs from these meetings.

Although we provide here a digest of our results, we ask readers to read Appendix A. Here, we describe the workshop format and give practical guidelines for implementing our pedagogic interpretation of how to run an RGD workshop with particular emphasis on getting participants to consider the linkages between the real-world complex system and how they cast that system into a game world that they design.

\subsection{Assessing the RGD Workshops}

In assessing the effectiveness of the RGD workshops, it is first necessary to state the circumstances under which they were held. We emphasize that the workshops had a number of objectives and were "processual-" rather than "product"-oriented. By this, we mean the workshops were part of other ongoing project or organizational discussions and processes. Additionally, the workshops can be seen more as pilot testing the planning and pedagogic promise of RGD. Thus, the workshops did not fully test the RGD method to the exclusion of other workshop objectives. Neither were the RGD workshops utilized as standalone workshops to ensure that wholly new "knowledge products" were delivered in the form of new understandings of complex systems tangibly accepted and agreed on by all participants.

\subsubsection{Reflections on Workshop Efficacy by Facilitators}

Regarding facilitator perspectives, the workshops were held in a context where a lack of shared perspectives between stakeholders was leading to social, ecological, economic and organizational risks. (For example, the Stellenbosch workshop in 2017 occurred during a period of widespread concerns about water and drought in the Cape region). Through the workshops, the facilitators aimed to turn the heterogeneity in perspectives from an obstacle to communication into an enhanced shared understanding of the dynamics at play. Therefore, we needed to create deep discussions that gently uncovered and integrated a range of perspectives without entrenching existing conflicts. 
We believe that RGD proved an ideal tool for the focused aims of the workshops. Commonly, we saw that the process of designing games led to philosophical, almost existential, discussions of the issues at play. During the design process, the groups had to deal with issues such as "What are the most important risks?" (when deciding which risks were worth putting on cards), "What role does the government have in regulating users and use?" (when deciding which actors should be in the game) and "What is the reason for what is being done?" (when choosing win conditions). Crucially, however, players were not asked to state these questions or answer them definitively or publicly to the whole workshop. This made it possible for the smaller groups to gently uncover and think about the various possible answers to these and other questions without fear of "getting it wrong". Thinking about these various perspectives together led to deep questioning of underlying issues whilst avoiding strong expressions of causality, solutions and blame. Whilst both workshops brought up policyand research-relevant ideas, the discussion in Tzaneen was considered by the facilitators to be more thoughtful than the one at the larger workshop in Stellenbosch.

\subsubsection{Reflections on Workshop Efficacy by Participants}

The two South African "catchment resilience" workshops and the London WaterAid "water security" workshop aimed to kick-start a discussion about their particular subjects in a relatively informal setting. Although we did not conduct objective evaluations other than asking participants for their reflections on the workshops (see Box 2), our view was that RGD met the strategic objectives of the workshop organizers and the expectations of the participants. For example, WaterAid saw their 30 workshop participants agree that wider systemic factors were shaping water and sanitation services in urban and rural environments and that these were many, varied and "more than only climate change".

Box 2. A selection of participant reflections on the workshops in Tzaneen and Stellenbosch, in answer to the question, "What three things stood out for you today?"

\section{Tzaneen}

- Game design yielded significant insights into assumptions, perceptions and resulting designs of games to reflect real-world or idealistic-world scenarios.

- Stimulation of thought processes and looking at situations from a multifaceted point of view.

- The effectiveness of games to get to the bottom of people's mindset.

- $\quad$ The idea of playing a game to get people thinking together towards common goals. Stellenbosch

- $\quad$ First for me with the interactive creative games. Very powerful tool. Would like to learn more.

- The approach of the games stimulates thinking. I liked the tools/approach.

- Interesting way of learning (games).

- Using games to illustrate "real-world" issues that educate people.

- Very interesting to use games as a way of thinking and training.

\subsection{Assessing the Games Designed}

The characterizations of the games are given in Figures 1 and 2. Figure 1 focuses on the content of the games, whereas Figure 2, supported by Figure 3, gives some insight into the types of game mechanics players chose to design their game. In this paper, we use the term "game mechanics" to refer to the methods of interaction with the game state provided to the players (for further discussion of game mechanics related to serious games, see Proulx et al. [37]). Figure 2 displays which game mechanics are present in each game. The list of mechanics used was formed by listing the smallest number of mechanics required in order to accurately represent formal differences in rules between the games designed. 


\begin{tabular}{|c|c|c|c|c|c|c|c|c|}
\hline & Game & Name & Time-scale & Spatial scale & Actors & Resources & Role of money & Decisions \\
\hline \multirow{3}{*}{ 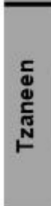 } & A & $\begin{array}{l}\text { Mutual Self-Interest } \\
\text { Game }\end{array}$ & Season & Catchment & $\begin{array}{l}\text { Agriculture, industry, environment, } \\
\text { domestic }\end{array}$ & $\begin{array}{l}\text { Water, capital, technology, } \\
\text { infrastructure, money }\end{array}$ & Means & Purchase, barter \\
\hline & B & $\begin{array}{l}\text { Sustainability board } \\
\text { game }\end{array}$ & Long-term & Catchment & $\begin{array}{l}\text { Domestic, regulators, } \\
\text { upstream/downstream agriculture }\end{array}$ & Water, money & Means and end & $\begin{array}{l}\text { Choose to advance } \\
\text { or receive money }\end{array}$ \\
\hline & C & That Dam Game & Month & Small catchment & $\begin{array}{l}\text { Agriculture, industry, forestry, } \\
\text { tourism, mining, domestic supply }\end{array}$ & Water & None & Bid for water \\
\hline \multirow{11}{*}{ 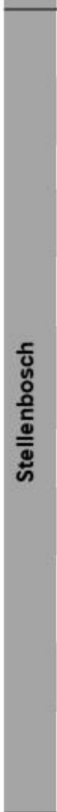 } & A1 & $\begin{array}{l}\text { Mountain to Sea } \\
\text { Apples }\end{array}$ & Several years & Catchment & Agriculture & $\begin{array}{l}\text { Cultivars, water, dam, } \\
\text { packhouse, cows, money }\end{array}$ & End & \\
\hline & A2 & DAM-IT water & Several years & Small catchment & Agriculture & $\begin{array}{l}\text { Cultivars, water, pipe, dams, } \\
\text { money }\end{array}$ & Means & $\begin{array}{l}\text { Build pipeline, buy } \\
\text { dam, buy cultivar }\end{array}$ \\
\hline & A3 & Drips and Drops & & & Agriculture & Money & None & Cheat (sometimes) \\
\hline & A4 & Agri-monopoly & $\begin{array}{l}\text { Year (summer- } \\
\text { >summer) }\end{array}$ & Group of farmers & Agriculture & None & Means & Buy/sell \\
\hline & B1 & Water World & Season & Farm each & Agriculture & Water, orchards & None & $\begin{array}{l}\text { Allocate water to } \\
\text { orchards }\end{array}$ \\
\hline & B2 & Water Wise & Long-term & Farm each & Agriculture & Water rights & None & $\begin{array}{l}\text { Accumulate water } \\
\text { rights through good } \\
\text { practice }\end{array}$ \\
\hline & B3 & Water-poly & Long-term & Farm each & Agriculture & Water, land, money & Means and end & $\begin{array}{l}\text { Buy land, buy } \\
\text { water }\end{array}$ \\
\hline & B4 & More Crop Per Drop & Couple of years & Farm each & Agriculture & Water, cultivars, money & End (partially) & $\begin{array}{l}\text { Plant and sell } \\
\text { produce, buy water }\end{array}$ \\
\hline & $\mathrm{C} 2$ & Water for Wealth & One season & Farm each & Agriculture & $\begin{array}{l}\text { Water, cultivars, money } \\
\text { (though resources play a } \\
\text { tangential role) }\end{array}$ & End & $\begin{array}{l}\text { Choose which } \\
\text { piece to move }\end{array}$ \\
\hline & C3 & Amanzi & $\begin{array}{l}\text { Year to many } \\
\text { years }\end{array}$ & Farm each & Agriculture & Water & None & None \\
\hline & $\mathrm{C} 4$ & Waterwise farmer & Many years & Farm each & Agriculture & $\begin{array}{l}\text { Pipe, plant material, } \\
\text { boreholes, land, water, pump, } \\
\text { store, irrigation, money }\end{array}$ & Means & $\begin{array}{l}\text { Collect resources, } \\
\text { give tips }\end{array}$ \\
\hline
\end{tabular}

Figure 1. Game content summary. 


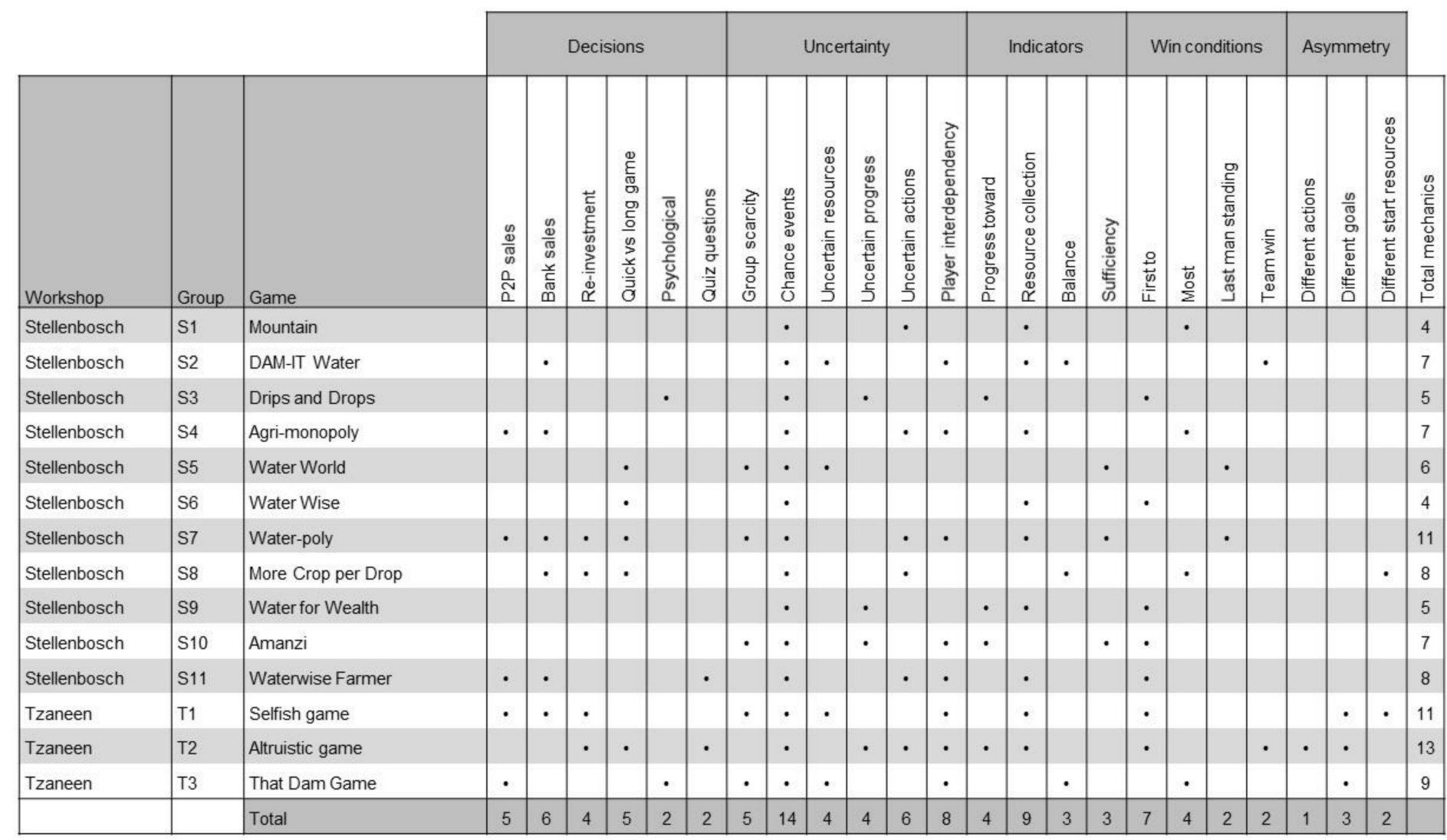

Figure 2. Game mechanics summary. 


\begin{tabular}{|c|c|c|}
\hline Category & Mechanic & Explanation \\
\hline \multirow{6}{*}{ Player actions } & P2P sales & Players can buy, sell and trade resources with each other \\
\hline & Bank sales & Players can buy, sell or trade resources with a central bank \\
\hline & Re-investment & Players can invest in things which advantage them within the game (other than being part of a win condition) \\
\hline & Quickvs long game & Players have to make trade-offs between short and long term gains \\
\hline & Psychological & Some mechanics depend on the psychology of players (cheating, bluffing, guessing what the other will do, bartering) \\
\hline & Quiz questions & Players can use real-world knowledge to benefit them in the game \\
\hline \multirow{6}{*}{ External factors } & Group scarcity & There is a common pool of resources which is limited/insufficient for all players to meet their goals \\
\hline & Chance events & Singular events happen during the game (through cards or board spaces) \\
\hline & Uncertain resources & Players are assigned random amounts of resources during their turn \\
\hline & Uncertain progress & Players make random amounts of progress towards a goal during their turn \\
\hline & Uncertain actions & The actions a player can take are randomly determined (e.g. by the square they land on) \\
\hline & Player interdependency & Players are affected by the actions of other players (P2P sales plus others) \\
\hline \multirow{4}{*}{ Scoring } & Progress toward & Player success is measured by spatial progress along a board or similar \\
\hline & Collection & Success is measured by accumulation of resources \\
\hline & Balance & Success is measured by obtaining a balance of two or more factors \\
\hline & Sufficiency & Success is measured by resources not dropping below a certain threshold ("staying alive") \\
\hline \multirow{4}{*}{ Win condition } & First to & The first player to reach a certain position or obtain a certain amount or combination of resources wins \\
\hline & Most & The player with most of a resource or score at the determined end point of the game wins \\
\hline & Last man standing & The last player left in the game after others have been put out of the game by insufficiency wins \\
\hline & Team win (sufficiency) & All the players win or lose as a whole against the game by succeeding or failing to meet a win condition \\
\hline \multirow{3}{*}{ Asymmetry } & Different actions & Players can do different things depending on their roles \\
\hline & Different goals & Players need to achieve different things to win \\
\hline & Different start resources & Players start with different amounts of resources \\
\hline
\end{tabular}

Figure 3. Explanation of the game mechanics in Figure 2. 


\subsubsection{Content: Real World Elements Expressed in the Games}

We observed (Figure 1 and Table 1) that in the Tzaneen, SA workshop on catchment/agricultural resilience, nearly all the games involved a single resource (water) to be distributed amongst multiple actors (agriculture, the environment, etc.) by a number of means and negotiations Whereas in the Stellenbosch workshop, also on catchment/agricultural resilience, many games involved a single actor (usually a grower) managing multiple resources (knowledge, water, labor, capital and so on). In other words, in the former, designers were balancing the allocation of a key resource (water) determined by climate and society, but in the latter, game designers were optimizing agricultural production in the face of constraints. Looking at the spread of games (Table 1), it is interesting to note that all of the Tzaneen games involved multiple types of water users, whilst none of the Stellenbosch games did.

Table 1. Games by numbers of users and resources.

\begin{tabular}{ccc}
\hline & Single User & Multiple Users \\
\hline Single resource & S03, S06, S10 & T03 \\
Multiple resources & S01, S02, S04, S05, S07, S08, S09, S011 & T01, T02 \\
\hline
\end{tabular}

The role of money was also interesting-10 out of the 14 games used money in some way. Of those, it was used as a means to an end in four cases, an end in itself in three and both a means and an end in two. In Drips and Drops (S03), players accumulated money, but it did not affect the result of the game (see Figure 1).

An examination of the games revealed the implicit or explicit temporal and spatial frames taken by the groups. For example, some groups emphasized today's reality, while others saw winning via arriving at or playing within an idealized tomorrow. Some games (and rounds within games) reflected a short seasonal view of the real world, contrasting with a few games that did not specify a time frame but certainly implied a long-term process. Some took a single farm as an object of analysis, while others focused on an entire catchment.

\subsubsection{Game Mechanics Used to Express Real-World Dynamics in the Games}

The analysis of the game mechanics, based on Figure 2, shows that although some games were similar, none had an identical mix of mechanics. For example, there were several "snakes and ladders" type games where the object was to reach the end of a board first, subject to various obstacles and aids, but they were all different in that some included the possibility to be put out of the game, and one included the psychological element of cheating/bluffing.

Counting the number of mechanics identified in each game is a crude measure of complexity, especially since the choice of which mechanics to list is ultimately up to the researcher, but it is interesting to note that all three Tzaneen games, developed during the smaller workshop, were in the top four most complex games measured by number of mechanics.

While some games provided a rich variety of decisions players could make, others relied entirely on chance. Buying and selling was a common action available to players, used in seven games. In four of these, players could sell either to each other or to a "central bank". Other common themes were decisions between short-term and long-term gains (used in five games) and reinvestment in components that would increase a players' agency in the game (in four games).

Chance events were used in every single game, and groups used them to bring in a wide range of external factors, from exchange rate fluctuations to hangover-related productivity fluctuations.

Scoring (measures of player success during the game) was mostly based on resource collection (including money) (nine games), followed by progress along a track (four games), with three games also rewarding creating balance between a number of factors and maintaining sufficiency ("staying alive").

We saw three dimensions of "win/winning conditions": (1) the metric of success, such as spatial progress towards a goal (e.g., along a track), collection of resources in the face of competing demands 
or maintaining a minimum level of a resource; (2) the definition of the point at which a winner "wins" (when a player reaches a target, at a set point in the game or when all other players have "died"); and (3) whether the win is individual or collective. By these dimensions, no two of the resilience games developed in the South Africa workshops had the same win condition. (Also interesting is whether winning a stage of the game gives a player an advantage and additional agency in winning the whole game, an example being the mechanism used for games like Monopoly and Settlers of Catan.) Winning was mainly determined by the first player to reach a certain state (seven games) or the player with the most of something (four games). There were also two "last-man-standing" games and one cooperative game where the team wins as a whole against the game. Asymmetry in the games (consisting of differences between players in terms of the actions players could take, their end goals or their starting resources) was also revealing. These asymmetries were used by the game designers to reflect imbalances between actors in the real world. For example, a player acting as the "government" can do different things to a player acting as a "grower". The three Tzaneen games were the only games to show deep asymmetry, although the Stellenbosch game "More Crop per Drop" had slight asymmetry in a random allocation of starting crop varieties.

\section{Discussion}

\subsection{Discussion Question 1: Value of RGD for Workshop Participants and Organizers}

To discuss the first question, we use five subsections to illustrate how RGD can expose system components and mappings, perspectives on success and winning and interpersonal dynamics in ways that are accessible to both workshop participants and organizers as well as building trust and relationships. In this way, the method (1) enables heterogeneous perspectives to be meaningfully uncovered and discussed and (2) encourages these to be integrated into a common mental model, delivering two ingredients or inputs required for feeding into sustainable systemic change.

\subsubsection{Exposing Tacit System Maps: Boundaries, Internal and External Components and Risks}

The games provided both researchers and participants an extensive set of issues the participants believed to be relevant, obtained by listing the actors, decisions, resources and indicators used in each game. They also gave an idea of which aspects were considered "within the system boundary" and within the control of actions carried out by putative players and which were considered external and/or imposed, for example, implemented by dice or chance cards. In particular, it was interesting to note which aspects were near-universally left to chance (e.g., rain) and which were treated both ways (e.g., government decisions). These tensions gave a glimpse into how participants negotiated their mental models of the system and the extent to which players were "masters of their own destiny" or were at the mercy of dice rolls or event cards. For example, the discussion on whether government decisions should be drawn from the same deck as weather events showed that some actors felt so distant from government decisions that they could be treated as random events. In addition, participants discussed which other aspects of the game were affected by randomness and whether this translated to a real-world comparison by looking at their successes within their system. However, it should be noted that in some cases, chance cards were probably used as an "easy" way to introduce complexity into games.

Furthermore, workshop participants gained most from gaining access to others' implicit and/or tacit perspectives and meanings through the game design and discussion. In other words, noting what is implied or is not said, or what is not designed, is informative. The range of perspectives illustrated through the games can be taken to indicate a "conservative spread" of participant perspectives. For example, we can say that the workshops showed that catchment-oriented and farm-oriented perspectives exist; supply-chain-oriented views may also exist, but these were less prevalent amongst these participants, as no games took this as their focus. A slight limitation in the spread of perspectives expressed is a likely but inevitable product of the orientation sessions (e.g., "baby steps") prior to 
the start of the designing activities. Even though facilitators were at pains to ask for imagination to be applied, we accept participants took clues from what they interpreted the workshop and games to be about. It was interesting that the Tzaneen games were at the catchment level, whereas the Stellenbosch games were largely at the farm level despite both workshops being facilitated similarly. Perhaps the greater degree of trust and familiarity between participants at the smaller Tzaneen workshop enabled groups to tackle deeper issues and stray further from the comfortable scaffold of games they already knew.

An examination of the choice and arrangements of materials produced by the participants invited further discussion on real-world systems. For example, by asking if game-world resources came from a finite shared pool or a bottomless "central/external bank", designers were questioning whether this reflected resource constraints in the real world. The layouts of boards sketched also reveal the "closeness" of certain actors or the difficulties of doing certain things. For example, one resilience game in Tzaneen involved a "collaboration" track that was longer than a strict regulatory path, suggesting that collaboration was a slower way of reaching a goal. However, there were other rewards, such as durable sustainable outcomes, for choosing this slower track.

\subsubsection{Winning: Perspectives on Success}

Another rich vein to mine was to consider how winning in the game world told us something about the real-world system. A key starting question, “What does winning look like?" (see Appendix A), prompted the game designing process, leading to more sophisticated questions such as "To what extent does the accumulation of resources grant players extra agency in the game, and how is user agency in the real-world system expressed?". Even a short game design workshop can throw up a number of interesting win conditions, for example, one player winning against the others or all the players winning against the game.

Again, it is important to apply thoughts brought up in this discussion to the real world, asking what motivates different actors and different perspectives on success. One participant in Tzaneen noted that his group had set out to make a collaborative game but ended up creating a competitive game because "it's just so much more fun". This could suggest why competition seems to come more easily than collaboration in the real world as well.

\subsubsection{Human Dimensions}

The games can also be analyzed by looking at intended game roles and behaviors. For example, we noticed that some games involved starkly interpersonal elements, such as collaboration, haggling or bluffing, and that sometimes players were not all "created equally" (with often downstream or weaker players identified at the outset). These behaviors, and how they illuminated the human dimensions of complex systems, proved to be ideal subject matter for the whole workshop to discuss towards the end of the day.

\subsubsection{To What Extent Can We Connect the Game World with the Real World?}

The plenary discussions held in the latter half of the workshops further reflected on how the games represented the real world. For example, most important was to try to tease apart whether each game tried to represent a "future ideal" or the "current status quo". Furthermore, it can be fruitful, though difficult, to determine to what extent the designed games truly represented a group perspective arrived at on the day or, by contrast, whether the game designing was prejudiced by one or two participants' prior game experience and their pre-existing views on the complex system. Also prior to and during the plenary discussion, it was useful to note the discussions held around each group's table on the extent to which their game was tied to "reality". For example, the Tzaneen games were complex and dissimilar to existing games known to the researchers, suggesting they were a good representation of the participants' perspectives on the resilience and governance of their catchment. However, this was generally not the case in the Stellenbosch workshop. 


\subsubsection{Additional Benefits: Building Trust and a Shared Vision}

On an interpersonal level, both sessions in South Africa appeared to be invaluable in terms of increasing trust and empathy between participants. Feedback suggested that participants grappled with difficult and personal issues with less guardedness than would be expected in a workshop like this. This could be due to a "leveling" effect caused by all the participants taking on a group task (game design) to which they were all new. The playfulness of the game components and their association with shared childhood memories would also have contributed to the reduced guardedness. Reliving these shared memories may also go some way towards building the desire for a shared vision of the present and the future-a sense of "we are all in this together". One participant a year after the 2017 Tzaneen workshop remarked that he had "talked about it (the subject of resilience) several times with (another participant) since the workshop", pointing to relationships strengthened by the workshop.

\subsection{Discussion Question 2: "Under the Hood"-How Does RGD Work and Function?}

Using four subsections, we consider how RGD works "under the hood" to productively expose and integrate participant perspectives. This answers our second question on how RGD functions and brings new insights to the field of serious games.

\subsubsection{Rapid Trust Pedagogy}

We reflect on the way in which the RGD works pedagogically to deliver rich knowledge-querying discussions about complex ideas in a relatively short space of time. To do this, we make two conjoined observations about our short-format approach: the first is the rapidity and short time span of the sessions, and the second is the trust placed in the participants that they will generate a board game in only 60-90 $\mathrm{min}$. The term "rapid trust" captures the quick prototyping of games, in sharp contrast to games that, while they might last only an hour or two, are "predesigned" and fit a longer process of discussion. Thus, an aim of our short format is that the preconceptions that players arrive with should and can be rapidly cracked open and added to.

By "trust", we do not refer to its normal use, which is that by playing games, users build trust between themselves [3]. Instead, we are interested in trust as a quality determinant of education, learning and teaching [38] that manifests itself in experiential "learning by doing" [3]. Notable in our format is the absolute trust that the organizers have that, aside from some initial tutoring exercises (the "baby steps"), small groups of participants are able to design sophisticated games without external input. We think pedagogic value can be seen in the way participants, puzzling the mechanics of devising a game world, think creatively and deeply about the nature of the real-world system to be reified.

\subsubsection{Playfully Designing Games}

While one might argue that, "games are to be played rather than designed", we observed a surprisingly rich and playful quality to the 60-90 min spent designing the game(s). It seems the aims, ethos, structure and products of an RGD workshop stimulate a creative and playlike process, echoing arguments by [39] drawing on March's "technologies of foolishness" [40]. We interpret this as follows: that there is a fundamental essence of "absorbed puzzling out" in the designing of a game. In other words, game designers, in group discussion, recalling games played earlier in life and recognizing the need to deliver and present a working model of a playful game in a gently competitive atmosphere, discuss and elucidate system phenomena with positivity and in "good spirits".

Three other overlooked factors that foster both "rapid trust" and a "playful" workshop include (1) preworkshop communications informing participants of aims and content; (2) the facilitative orientation sessions carried out before the design activity, see Appendix A and Marsh [41] for a discussion of issues related to duration and scheduling of sessions, which is rarely detailed in the literature, with the exception of Statler and Oliver [27], who refer to warm-up facilitative activities 
used before "serious play" sessions); and (3) the implicitly competitive atmosphere in the workshop, wherein tables/groups produce their games within an allotted time and present them to the others. "Contestation" between small groups is similarly highlighted by Prensky [42] in this regard.

\subsubsection{Expressing the Complex System as a Game Metaphor}

We believe that dynamically expressing the complex system as a game metaphor happens in six ways: (1) the drawn design of the game on the poster paper; (2) the choice of games materials, which in turn define elements of types and numbers of players, chance and risk; (3) the discussions about mechanics, roles, rules and objectives; (4) how players imagine they might experience the game and respond to game events and go on to win or lose; (5) the explanation of the game dynamics when the game is presented to other groups; and critically, (6) the plenary comparison between the different games witnessing how a complex system can be designed in different ways. It is these six parts that work in combination to create a very rich, social and dynamic process.

Designing games offers a chance to create a material analogy or language that demands participants ask deep questions about the system's character that they might not have the words to express in another way. In this way, RGD creates "meaning" via the construction of dynamic mental models of wider complexity, as argued, for example, by [1]. We often saw participants lean on the game being created in order to express complex concepts, and this common "language" also reduced the power imbalance between experts and nonexperts. For example, in one workshop looking at plastic packaging in the fruit and vegetable supply chain, a participant asked, "But the shop-is it a player, or is it the board?" Everyone in their group knew what they meant, and they were able to reach consensus on the issue. The same question outside RGD might be, "In this particular perspective, are we treating the shop as an actor within the system or as the system and its boundary?" which is unlikely to be asked (or even understood). Yet the two perspectives reveal the different understandings of those people who work at the shop level and see it as a system and those people who work at larger scales (e.g., on value chains) and see it as an actor. Our interpretation is that through the materiality of a board game, with its components, roles and rules, RGD obliges these meanings to come to the surface. It was the fourth (plenary) and fifth (post) stages of analysis that allowed participants and facilitators to "import" these ideas into discussions about the real-world socio-ecological systems.

\subsubsection{Interrogating the Game World Iteratively as a Group}

Looking back on our workshops, groups rarely designed the drawn board, the materials and the game events in order but instead iteratively went back and forth between them. During this process, the game world was repeatedly compared against participants' multiple perceptions of the real world, and discrepancies were resolved. Herein lies much of the value of the process: as the group interrogated the game world in front of them, different perspectives on the real world were made explicit. When inconsistencies were discovered, the group changed the game; however, this also brought changes to their perceptions of the real world. For example, a group might realize that in the game, there is no incentive for a player to undertake a certain action, and this can help build understanding of why certain apparently desirable actions are not undertaken in the real world.

\subsection{Discussion Question 3: Contextualizing and Comparing RGD}

In answering the third and final discussion question, we compare the advantages and disadvantages of RGD against playing predesigned games, using other non-game-based "serious play" methods and designing video games. We also discuss in which contexts RGD is especially suitable and how comparisons between game methods in the future might be strengthened.

\subsubsection{Comparison with Other Methods}

An interesting distinction between play-focused methods using "predesigned" games and design-focused methods such as RGD is how they express actor roles and/or the identity and schema 
of the complex system. We surmise that predesigned games may be vehicles best suited to expressing actor-level perspectives and roles. Thus, in predesigned tabletop games, players are expressing role behaviors and opinions that are semiflexible within a predefined format. In other words, they see the system identity as role-players and actors. This contrasts with the RGD format, which is more flexible for puzzling out and expressing the schema and identities of a complex system within which actors and roles are simultaneously or subsequently placed and defined. That said, we did observe that when designing games, the designers began to "proto-adopt" some of the roles they were "designing into" their games (such as upstream and downstream water users).

To illustrate, as role players or as players in a predesigned game, roles and behaviors come to the foreground. Roles are visible and stated, and examples are equal players, bankers, unequal players (perhaps geographically determined), defenders, attackers and so on. Out of these roles, game activities emerge, of which examples are bartering, working together, competing, lying, negotiating and accumulating. These activities are further qualified by behaviors shaped by the role and the player's own personalities. Examples include passive, secretive, aggressive and trustworthy behaviors. All in all, the gaming experience, rich and enjoyable, is clearly human, immediate and processual.

However, these roles and behaviors contrast with our observations of rapid game designers. Here, the latter were attempting to work out how to distill or express a real-world system into a game-world system that was designed but not played. The design discussion was more about reflecting on the schema or character of the system to be condensed into a game and was less about fulfilling the roles and rules of an already-designed game.

We believe RGD to be unique within "serious play" methods (such as "rapid prototyping" or "Lego serious play") because although the subject material is or can be highly abstract, the materials are physical tabletop game components (see Appendix A). Examples of abstractions of complex systems seen in the RGD workshops include ideas such as resilience, scale, water security, institutions, trade-offs, participant learning and governance. Thus, our view is that RGD appears to combine the benefits of both materiality and abstraction. Schulz et al. [29] found that abstract toolkits were more effective than themed toolkits, as they required more narrative from participants. Our approach, however, uses tabletop game components as an open-ended material toolkit, which, together with rules, encourages the practical expression of more dynamic elements of systems (competition, collaboration, cheating, winning and so on) but is sufficiently abstract to allow participants the freedom to consider the schema of their complex systems and to select facets of them.

Video games are now as popular as or more so than tabletop games and so could provide an alternative format in terms of designing. However, we believe that tabletop games are more suitable for seeing complex systems via RGD because designing the game prototypes requires no special skill or time investment. Furthermore, there is no computer language preparation beforehand or hardware in the form of computers or the requirement for an electricity supply. As such, we believe RGD workshops using physical games materials are more accessible, quicker and more focused on conceptualizing the system. Additionally, having physical artifacts on a table that participants can all simultaneously interact with aids group communication greatly.

\subsubsection{Where Is RGD Particularly Useful?}

In our experience, RGD is most useful where there is a need for a diverse range of people with often deeply and tacitly heterogeneous perspectives to come together and find ways to create change. This includes many sustainability challenges, including the management of limited resources; trade-offs affecting starkly different groups, places or generations; and the need to understand or coordinate change taking place at an unprecedented pace and scale.

As participants' own knowledge and experience forms the content of the games, RGD is more suited to groups containing at least some members with close connections to the topic. The short format of RGD makes the method particularly useful when working with stakeholders who have limited time available. The method has a leveling effect and prevents technical experts from dominating the group. 
Dynamic system elements and ideas are easily expressed using the method. Therefore, RGD can assist siloed and/or diverse groups of stakeholders build shared understandings and find common solutions in strongly dynamic systems. Other applications are, of course, possible. For example, for a novice group, one could use RGD to explore preconceptions and gently expose gaps in knowledge prior to a longer debrief where participants could learn more.

\subsubsection{Future Work to Compare Methods}

An interesting opportunity for further work would be to run parallel workshops comparing RGD with other methods of using games to explore complex systems and ideas. This would allow for an experimental control to be established to discern learning outcomes connected to the method employed. Unfortunately, due to lack of time and other resources, this was not possible within the frameworks of the projects where we have used RGD so far.

The value of the games designing format exists in transforming the experiences of games designing back into the "real world". However, not surprisingly, this transformation, not being an immediate, linear and direct "cause and effect", is not easily trackable. Moreover, our workshops were not set up to monitor post-workshop changes on participant behaviors. Contact could be maintained with workshop participants to ascertain where and how the ideas and relationships developed during the workshops fed into real-world transformations.

\section{Conclusions}

To summarize, "rapid games designing" is a practical approach to discussing socio-ecological systems, sustainability, resilience and other related concepts. It results in games designed by groups of 3-8 people (important for discussions and building something together), uses an array of games equipment on the table, benefits from no or few guidelines on how the game should be designed (except for the "baby steps"), works within only 60-90 min and avoids the need to play the game but asks designers to explain how it might be played and what it is trying to achieve as a game. (As a part of this summary, we remind readers to turn to Appendix A).

What RGD provides is an accessible expression of multiple models of the system, perspectives on success and interpersonal dynamics whilst helping to build trust between participants. This creates the group understanding required to lead change. The rich variety in the games indicates that the rapid game designing method was successful in demonstrating the wide variety of perspectives present in the room, and the discussions during the process show that the exercise provided ample room for these perspectives to be compared and integrated. Some of the more "advanced" features exhibited by some games (deep asymmetry between players, competing group and individual goals and interpersonal elements such as bluffing and cheating) suggest that the exercise facilitated a deep discussion of the system beyond the consideration of actor roles and the trade-offs and negotiations between them.

We surmise that RGD works by placing pedagogic trust in participants, a playful atmosphere, the group construction of a physical representation of a metaphor and an iterative process of interrogating this representation. Furthermore, with respect to knowledge building, our conclusion, echoing Valente and Marchetti [43], is that rapid designing of tabletop games is a highly dynamic, effective and flexible method to unpack and discuss complex systems and components and their abstract (or "academic" to some people) conceptualization and "meaning" [1]. In essence, RGD does this by asking participants to construct a metaphor of a metaphor. Examples of complex systems were seen in the workshops played to date and included the sustainability of food or food chains, the resilience of catchments facing environmental change and rising water demand and the management of water and sanitation services. Examples of "meaning" were seen in workshop discussions, for example, in South Africa, on how resilience outcomes are distributed between actors within a built environment and, with WaterAid, on the meaning of water security. We believe the format is highly adaptable and generalizable; it can be applied to different types of systems and system problematics as well as accommodating a diverse range of participant stakeholders. 
Although rapid game designing could not be empirically compared to other methods within this study, we surmise that it could have advantages over playing predesigned games where system-level as opposed to actor-level thinking is required and over other non-game-based "serious play" or "rapid prototyping" methods where system dynamics are significant. Regarding outcomes, these echo the benefits seen by other scholars in the field of serious games [2]. Notably, the format (a) was successful in terms of time management as well as being engaging, creative and thought-provoking; (b) led invariably to diverse game designs, some of which were very sophisticated; (c) inspired deep discussions about the conceptual nature of systems and resources; (d) showed how a room of tables/groups generated creative insights that could be further guided by facilitators; and (e) provided a memorable event as a stepping-stone for further communications and meetings within a longer deliberative process. As a part of this, some games could be further developed and played as full-fledged games.

Author Contributions: B.A.L. conceived of the rapid games designing format. J.C. analyzed the mechanics of the games in South Africa. Thereafter, both authors contributed equally to the writing and to the improvement of the format over the last few years. Both authors have read and agreed to the published version of the manuscript.

Funding: This research project was called "Increasing resilience to water-related risks in the UK fresh fruit and vegetable system". Called FF\&V for short, it was funded through the Global Food Security "Resilience of the UK Food System Programme" with support from the Biotechnology and Biological Sciences Research Council, Economic and Social Research Council, Natural Environment Research Council and Scottish Government (BB/N020499/1). We are very thankful to other members of the FF\&V research team whose insights and comments over the last few years assisted with this work: Tim Hess, Jerry Knox, Kate Pringle, Jon McCosh, Mlungisi Shabalala and George Garbutt. We appreciate the participation and contributions of the many tens of people who took part in the games designing workshops held to date. We are very grateful to the anonymous reviewers for their very helpful comments.

Conflicts of Interest: The authors declare no conflict of interest.

\section{Appendix A. Delivering a 'Rapid Games Designing' Workshop}

\section{Appendix A.1. Introduction, Background and Logistics}

This Appendix explains the delivery of a workshop that employs rapid game designing (RGD) to discuss complex ideas such as sustainability and resilience applied to environmental and human systems. (More information can be found at http://rapidgamesdesign.info) Photographs of games designed at recent workshops are found at the end of the Appendix.

For information, the initial assumptions are:

- Although the workshop assumes one day is available, the schedule here runs for about five hours with a lunch break in the middle.

- We do not cover the arrangements for setting up and hosting the workshop-e.g., details about email correspondence etc. are not included.

- We use the word 'dice' for singular and plural.

Appendix A.1.1. Pre-Workshop Preparation

Prior to the workshop, communications with participants allude to a games style format, but do not provide excessive detail that they would be designing games. We feel it important that all participants come to the workshop with no or few assumptions about what it entails for them as individuals so that they start from the same place, and so that they will not be anxious about whether they are capable of designing a game. Instead, pre-workshop guidance on key questions and readings are provided. Examples of the key sustainability questions include; "What does water security mean for water, sanitation and health (WASH)?" or "What does a resilient catchment look like?"

\section{Appendix A.1.2. Room Arrangements, Group and Table Numbers}

RGD works well for a meeting of between 10 to 50 people. The room should already have tables laid out so that on arrival participants immediately sit within groups of 3-8 people around tables. 
For example, with 30 or so people attending the workshop there would be about $5-6$ groups. It is worth thinking about arranging the groups in advance so that each group is as diverse as possible. In this way different world-views come into contact from the beginning. In this case a list of names can be placed on each table.

\section{Appendix A.1.3. Overall Scheduling of the Workshop}

The first 10 min of the workshop is taken up with initial statements and welcomes. After this, Stage 1 comprises four introductory activities in total lasting another 60-90 min take people to the point at which they start to design their own games. These are explained in four subsections below.

Generally, people start in Stage 2 to design games about an hour before lunch, with completion either before or soon after lunch. The early part of the afternoon is devoted to Stage 3 which involves presentations of the games before moving to Stage 4, a final plenary discussion, taking place about mid-afternoon.

Table A1. Outline of a 'rapid games designing' workshop schedule.

\begin{tabular}{cc}
\hline Welcome and introductions & $10-12 \mathrm{~min}$ \\
\hline Stage 1. Introductory technical presentations & $10-12 \mathrm{~min}$ \\
\hline Presentation-“why games?” & $10-12 \mathrm{~min}$ \\
Presentation —“what to be gamed?” & $10-12 \mathrm{~min}$ \\
Presentation-“how to design a game?” & $45-50 \mathrm{~min}$ \\
\hline Stage 2. Games designing exercise & $60-80 \mathrm{~min}$ \\
\hline Lunch or break & $30-60 \mathrm{~min}$ \\
\hline Stage 3. Presentations of games & $40-60 \mathrm{~min}$ \\
\hline Stage 4. Plenary discussion & $60-90 \mathrm{~min}$ \\
\hline
\end{tabular}

Appendix A.1.4. Support by the Facilitators

One to four workshop facilitators are on hand to assist with questions and note-keeping. This support records what happened during the day, assists creativity, encourages quieter people to get involved, and promotes the use of more of the games materials.

\section{Appendix A.1.5. The Games Materials Used}

Each table is provided with A0 or A1 poster paper and colored pens, to draw their game board (although a card game without a board would be equally valid) and a collection of games materials such as six-sided, 12-sided and 20-sided dice, blank dice for adding icons and marks, sand timers, counters of different designs, 'fake/play money', probability spinners, blank cards and playing cards. See Photo 1. Games materials can be found on-line, and to see what is available see this link: http://dice.co.uk/products.htm. 


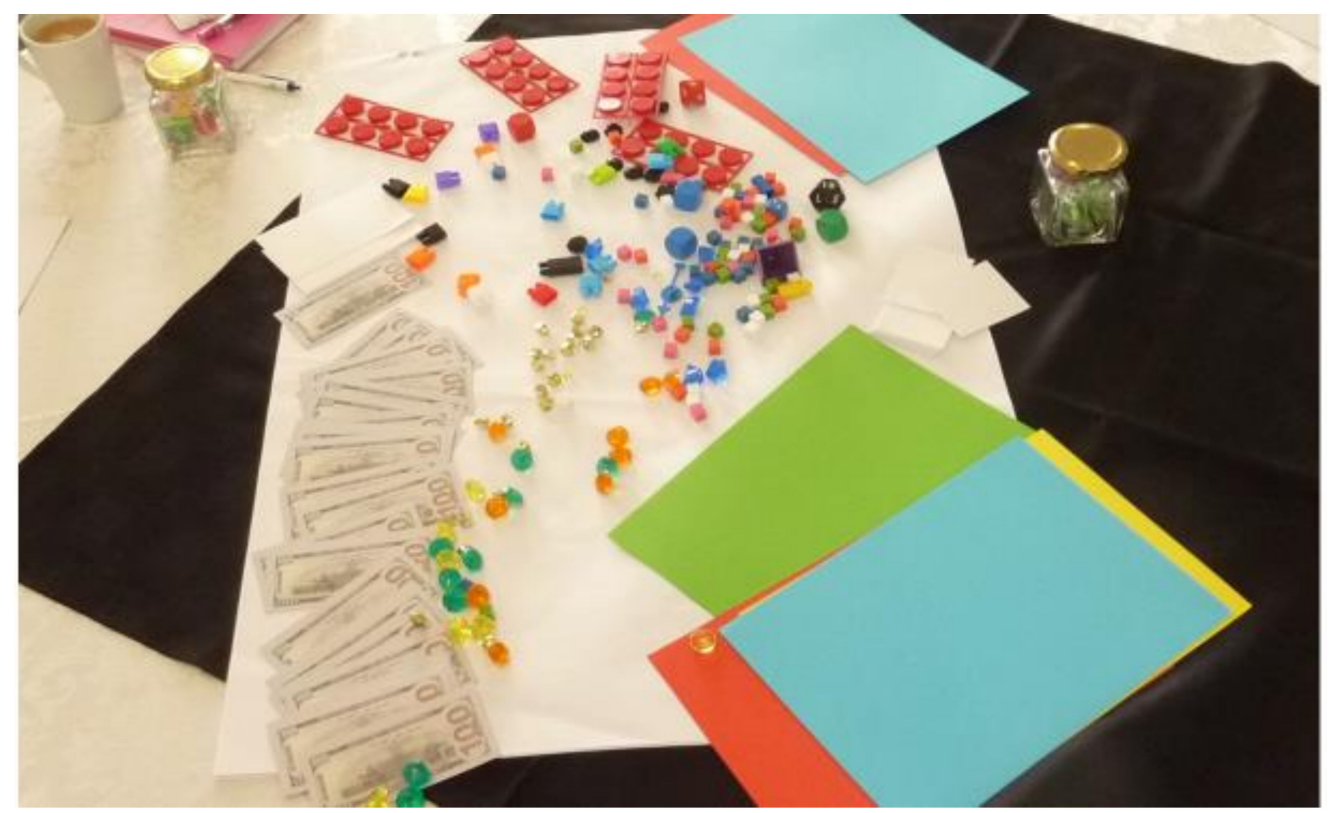

Figure A1. Games materials in readiness to be arranged into a game.

Appendix A.2. Stage 1: Introduction to Games Designing

Appendix A.2.1. Introductory Technical Presentations (10-12 min)

The first of the four introductory presentations starts with a quick initial technical presentation. This mini-talk ensure that everyone understands; (a) the reason for the workshop (e.g., for research purposes; promote stakeholder knowledge and participation, or to consider a new organizational strategy); (b) the general topic area pertaining to the workshop theme (e.g., sustainability, resilience or linking water security to water and sanitation), and (c) the general rules of discussion and 'contribution'; that everyone should offer their views, listen to others, and/or ask questions to clarify proceedings.

\section{Appendix A.2.2. Presentation-'Why Games?' (10-12 min)}

This second presentation covers the increasing use of games and what they try to achieve such as bringing people together for learning and discussions. Examples of games relevant to the topic can be used here, although it is useful not to go into the rules in detail to avoid 'tramlining' the groups into producing similar games. This session is also the appropriate moment to introduce two key ideas -the real-world and the game-world (see main paper).

Appendix A.2.3. Presentation-'What to Be Gamed?' (10-12 min)

The third presentation gives a range of technical information ensuring that participants know what system or concept is to be 'game-designed'. Examples include 'how water security and WASH intersect' or 'how water and food resilience might be expressed in a catchment'. While this presentation might revisit some of the material given in the introductory presentations, it must be finely balanced to refer to factors and dynamics that feature in the system to be designed but not tramline or prompt participants to think narrowly about their system and game.

\section{Appendix A.2.4. Presentation-'How to Design a Game?' (45-50 min)}

This fourth introductory talk is a critical part of the workshop. It takes participants from zero experience in designing games to attaining sufficient confidence and knowledge to create a game. We found that 45-50 min of staged learning in three parts achieves this. First, we ask participants to think about what players in a game are trying to achieve through the objective 'to win' (see Part 1 below). Second, in Part 2, we reinforce the ideas presented about the distinctions between the 'real-world' 
and 'game-world' and how the former is represented in or by the latter. In the third Part, we take participants through six exercises to practically understand the real and game-worlds and then to manifest parts of games or design a simple game. We use the term 'baby steps' to describe the six mini-exercises (see below). Through this process players arrive at the beginning of the game design part having already designed several game components, to give them the confidence they need to proceed with games design.

Part 1: Acquiring a Games Mindset—on 'Winning' (and Losing)

Winning or losing a stage or winning/losing the whole game is central to creating games that engage participants. In this brief presentation, it may be useful to ask for some feedback using games that participants are already familiar with such as Monopoly, although again avoiding heavily focusing on one game and "tramlining" the groups. Questions to promote discussion include:

- What do we mean by winning? What is the win objective?

- Defined by total win or relative win? First to arrive?

- By forms of accumulation? (Of money, marbles, score, a step forward on the game)

- Enabled by speed, strength, position, luck, information, turn, role, bluster, acting and mimicry

- To win, are negotiations mediated by (a) the players, (b) the game physicality \& interfaces (c) the game stages, roles and rules, and (d) the game mediator/observer?

- What are the consequences of not winning?

- Intermediate sequences and stages or trade-off positions?

Part 2. Understanding the Real-World vs. Game-World

A brief discussion between participants of actions and events to help distinguish the real-world (e.g., a drought) and a game-world representation of the real-world (e.g., for a drought "lose 10 counters", for a severe drought, "lose all counters").

\section{Part 3: The Six ‘Baby Steps' of Designing a Game}

These are the six elementary steps in getting participants to consider how the component parts of a game are put together. It is always worth reminding participants that they do not need to give physical and technical answers (e.g., droughts or boreholes) but also consider other concepts and abstractions (e.g., the role of informal and customary practices and law).

1. Start the baby steps by asking someone in the group to select a games world counter or token and to place it in front of their group and then explain the role or actor this token or counter might represent in the real-world (e.g., "this blue counter represents a water law judge or 'hydropower'"). After a few minutes the tables can shout out some roles they have imagined.

2. In the second 'baby step', using a photograph of a relevant theme (e.g., a dry landscape or some cattle around a borehole) as a prompt, ask participants to complete the sentence: 'Interpreting actions as players winning in the real-world and thinking about the resource system (e.g., WASH in a rural or urban community or growing a crop in the Sahel) express to your group 'how you/he/she/it 'succeeded/won' in the real-world when ... '. Then we provided an example such as "I won during a drought because I had access to freshwater from a borehole." (Participants are given 2-3 min working in their table groups to give another real-world example of how they 'won' or succeeded).

3. Ask the groups 'Select a dice from in front of you'. (Remember the dice is in the game-world). Then ask them to decide 'what does the dice represent in real-world terms?' (For example, the dice represents the rainfall pattern for the year). Now decide what the real-world outcome of 
rolling the dice is. (Remember the number on the dice is in the game-world). E.g., the number 'six' represents a flood. If a table does not already suggest it, you could add a second dice to represent another feature and therefore the impact of the outcome of the first dice. For example, one dice represents rainfall pattern and a second dice represents population density.

4. State or instruct: 'Select a blank card and write on it two related events': a real-world event and game-world event. An example is 'a drought' and 'deduct 10 points or lose $50 \%$ of your money'.

5. State: "A pile of counters on the table represents water in a shallow aquifer; taking only two minutes design a simple game to share this water to different players around your table." (An example might be that each person throws a dice and the person who throws the highest score has total control in deciding who gets the counters).

6. State: "Draw any diagram/squiggle/sketch on a poster paper". (An example is given by the facilitator). Allow the groups to create a diagram, then state again "Now explain how this might be the basis for a game." For example a large 'S-shaped line' becomes a path for players to move along from start to finish similar to 'snakes and ladders'.

\section{Appendix A.3. Stage 2: The Games Designing Exercise (60-80 min)}

Here the groups are instructed to now design a game that reflects the problem or system from any viewpoint or angle they see fit (or via a given angle if the workshop has this intention). Then the groups are left to their own discussion and time. From our experience this should last about $60-80 \mathrm{~min}$ and is unstructured. Group members usually start discussing, for about $30-40 \mathrm{~min}$, a problem to be gamed and how the game should capture that problem, followed by the remainder of the time drawing the game and devising rules of use. Groups often re-draw a clearer version of the game in the last five minutes of the allotted time. By the end, participants will have drawn a game template on the poster paper and define the use of game components, players and so on. The designers are also guided by a set of guidelines which also are returned to when presenting their game to other groups—see Box A1.

Box A1. Guiding and presenting the games.

These questions guide participants in both designing and then presenting their games. These are for guidance only-in reality the designing and presenting is more free-flowing.

- What is the game-world about? What 'real-world' is it rendering?

- What is the aim/purpose of your game?

- What are the materials \& what do they do?

- Who are the players? Do they have roles?

- What can the players do/how move? (Rules to move next stages/rounds)

- What happens then to the players at the stage/round (stage obstacles and or stage successes)?

- How do they win the game overall?

It is important to remind groups they are not required to produce a fully playable game, as this can lead to participants making "safe" choices such as employing a game they already know. This should be avoided as it leads to a more superficial discussion.

\section{Appendix A.4. Stage 3: Presentations about the Games by Each Table (40-60 min)}

This group discussion involves each table/group presenting their game design to the other tables/groups followed by quick 'questions and answers' to clarify the purpose and rules of the games. At the end of about one hour, each group should have presented their game to the other groups. This stage has turned out to be highly productive way of allowing both the game designers and their audience embellish and add to each design. It can also be useful to ask groups to briefly explain how they got to the finished game, including ideas which were discarded along the way. Recall, the guide in Box 1 can be utilized to help with these presentations. 
Appendix A.5. Stage 4: Plenary Discussion by Workshop Participants (60-90 min)

A second more substantive group discussion takes place after all the tables had finished their presentations and aimed to get a 'whole group' set of thoughts on the whole process of game designing and how it revealed new aspects about the resource/complex system. A good jumping-off point is a comparison of the games, and how different each game is. Discussion might also try to reveal issues and dimensions that were not included in the game designs.

\section{Appendix A.6. Stage 5: Post-Workshop}

\section{Appendix A.6.1. Analysis of the Games Designed}

Whilst as much of the "unpacking" of the games as possible should happen during the workshop, the notes, photographs and game materials created by the participants can be analyzed post-workshop to bring further insights relevant for research. The way this is done should be adapted to suit individual purposes, but some useful starting points are:

- "ARDI" analysis: listing Actors, Resources, Decisions and Indicators

- Win conditions

- Role of randomness

Once these have been listed for each game, the games can be compared to draw conclusions about the spread of worldviews expressed, and how these compare to each other and to the preconceptions of the research team.

\section{Appendix A.6.2. Workshop Analysis by Facilitators/Organizers}

The organizers and facilitators can also discuss the day and the outcomes from workshop. This discussion would examine the following key questions:

- Did the game workshop meet the original objectives of the organizers? How was this tested objectively?

- Did participants arrive at new understandings and/or provide new definitions of the subject matter that was 'rapidly game designed'? How was this verified?

- What immediate follow-up is required to sustain learning outcomes and actions?

- What improvements might be made in the future to the format and facilitation of a workshop where RGD is employed?

Appendix A.7. Two Reflections on the Workshop Logistics

Appendix A.7.1. Group Size

A notable difference between the two South African workshops was the size of the group which had implications for outcomes. In Tzaneen in 2018 workshop attendance was small enough (approx. 25) for the entire group to gather around a sub-group and their game. This meant that the entire group saw and shared in all the games developed on that day. By contrast, in Stellenbosch with 90+ people divided into 10 groups, the room was further divided into three for the presentation of the games. This meant that each participant saw only a third of the games developed making it difficult to generate "whole group" learning. The group size also had practical implications for the quality of facilitating and note-taking. Our experience suggests a maximum workshop size of around 20-50 participants with 3-5 facilitators works best.

Appendix A.7.2. Materials and Prompts

Facilitators must be aware of the stimuli they are planting in participants' minds either through the content of the introductory and technical presentations and the choice of materials provided. 
To illustrate the latter, providing play money may encourage players to include money. It may be preferable to exclusively use "abstract" materials to avoid leading participants inadvertently. They can use a certain color of block, say, to represent money. In the 2018 Tzaneen workshop, players were also provided with a sheet, using the prompts in Box 1 above, to fill to summarize their game, which was intended to serve as a record and a prompt if they were stuck. However, participants tried to use it as a starting point which appeared to dull their discussion. These worksheets were not used again in subsequent workshops.

Appendix A.8. Photos of Designed Games from Recent Workshops

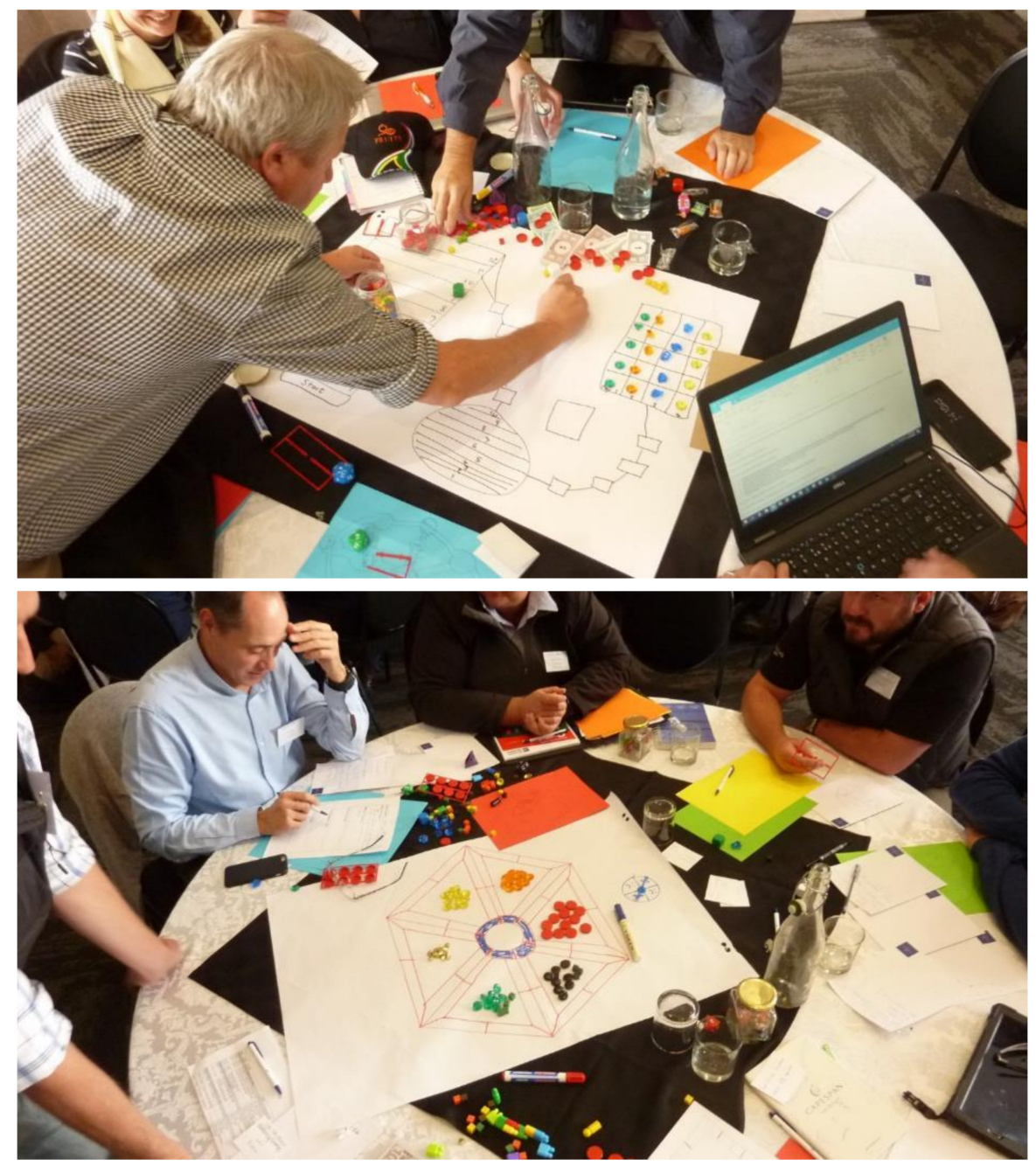

Figure A2. Photos of water and catchment resilience games (South Africa). 


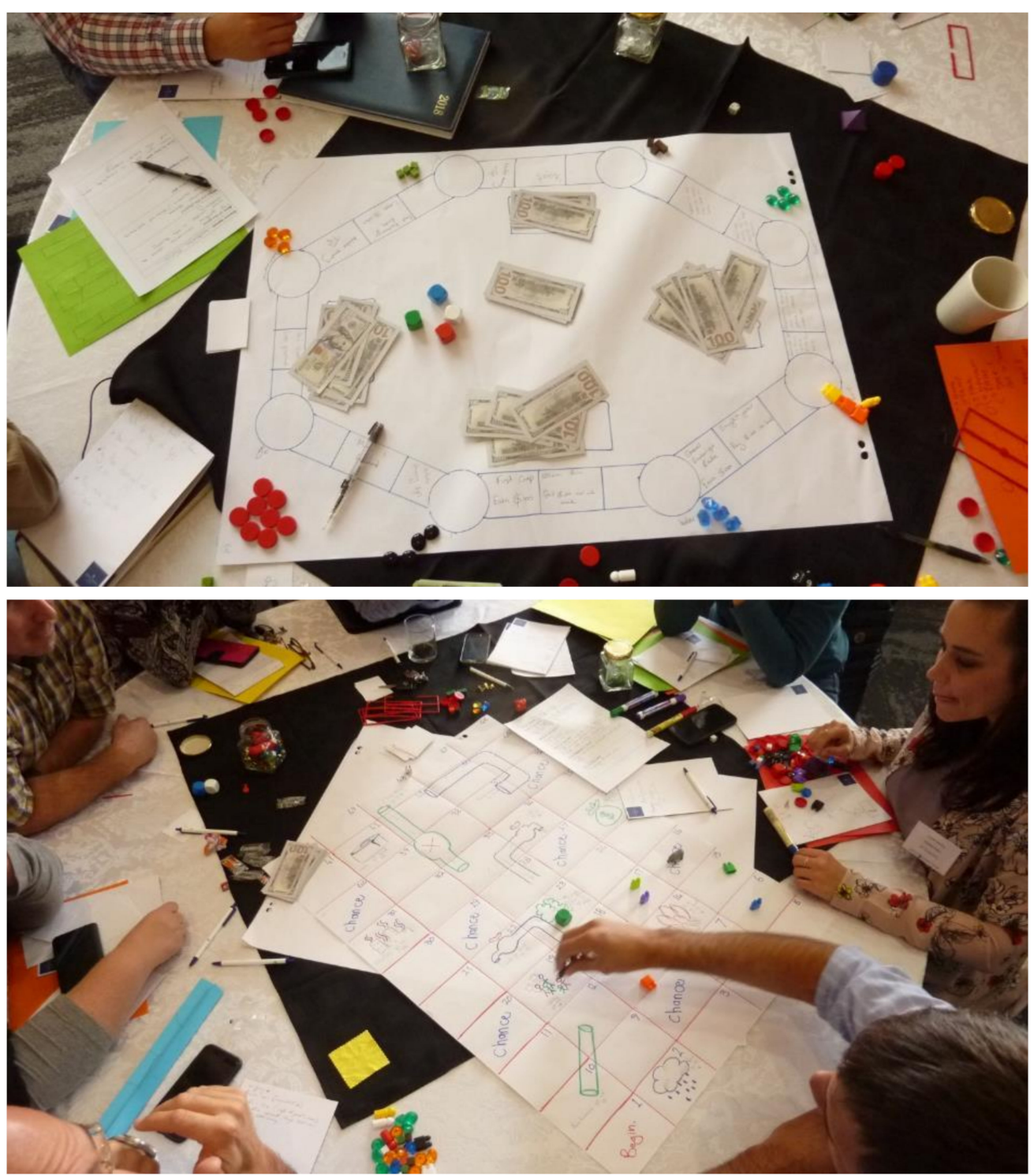

Figure A3. Photos of water and catchment resilience games (South Africa). 

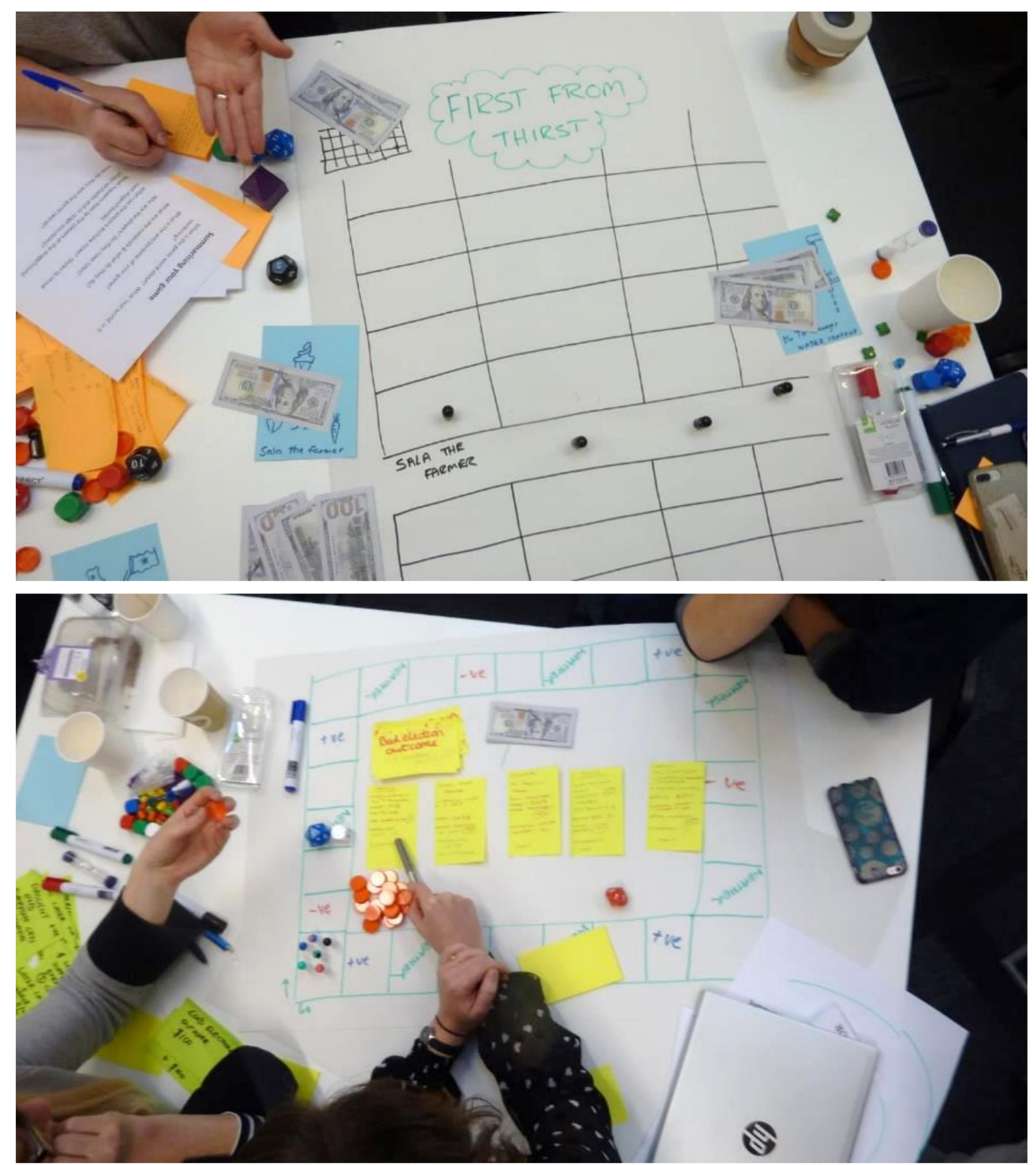

Figure A4. Photos of water and sanitation (WASH) and water security games (WaterAid London). 

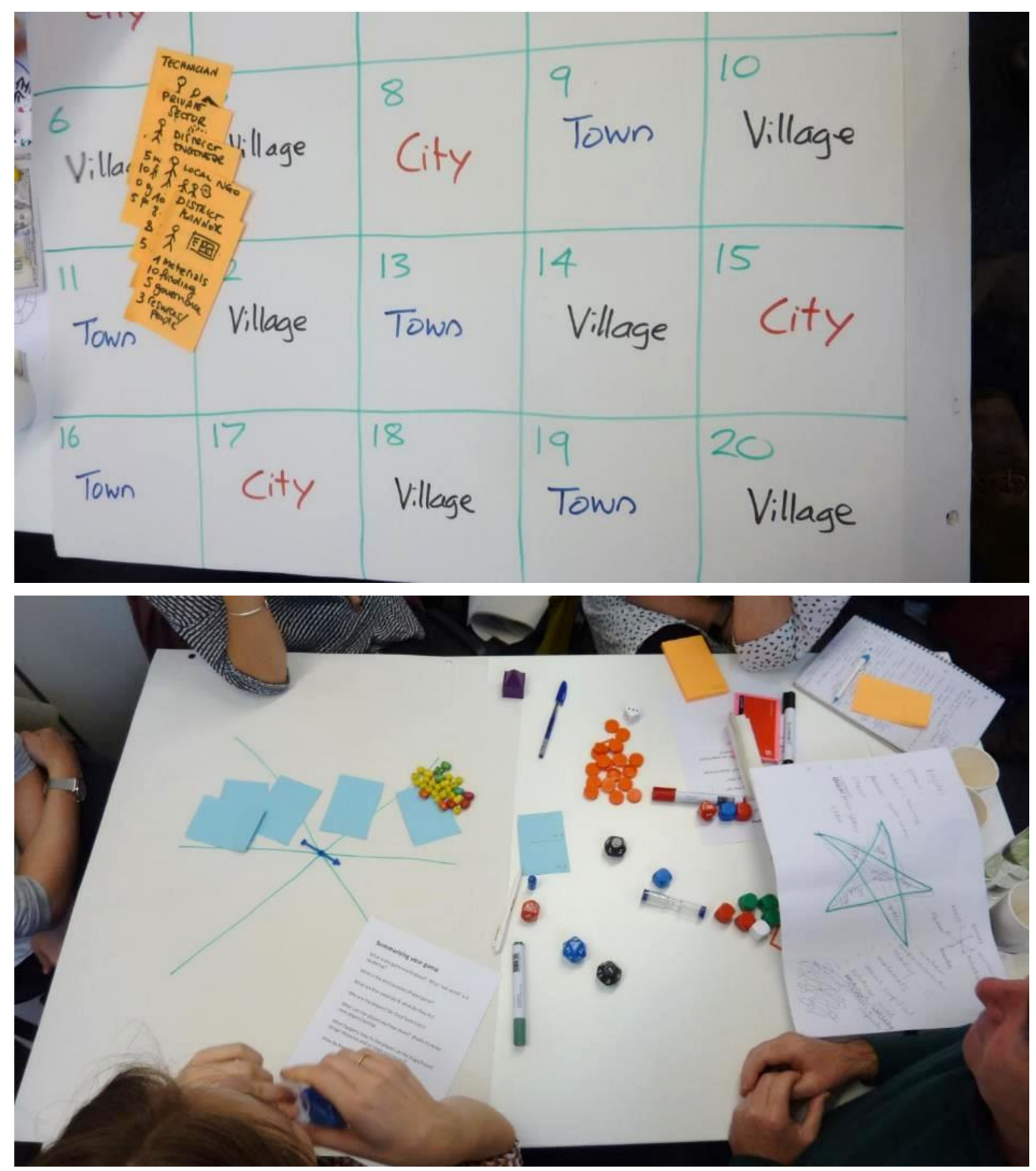

Figure A5. Photos of water and sanitation (WASH) and water security games (WaterAid London). 

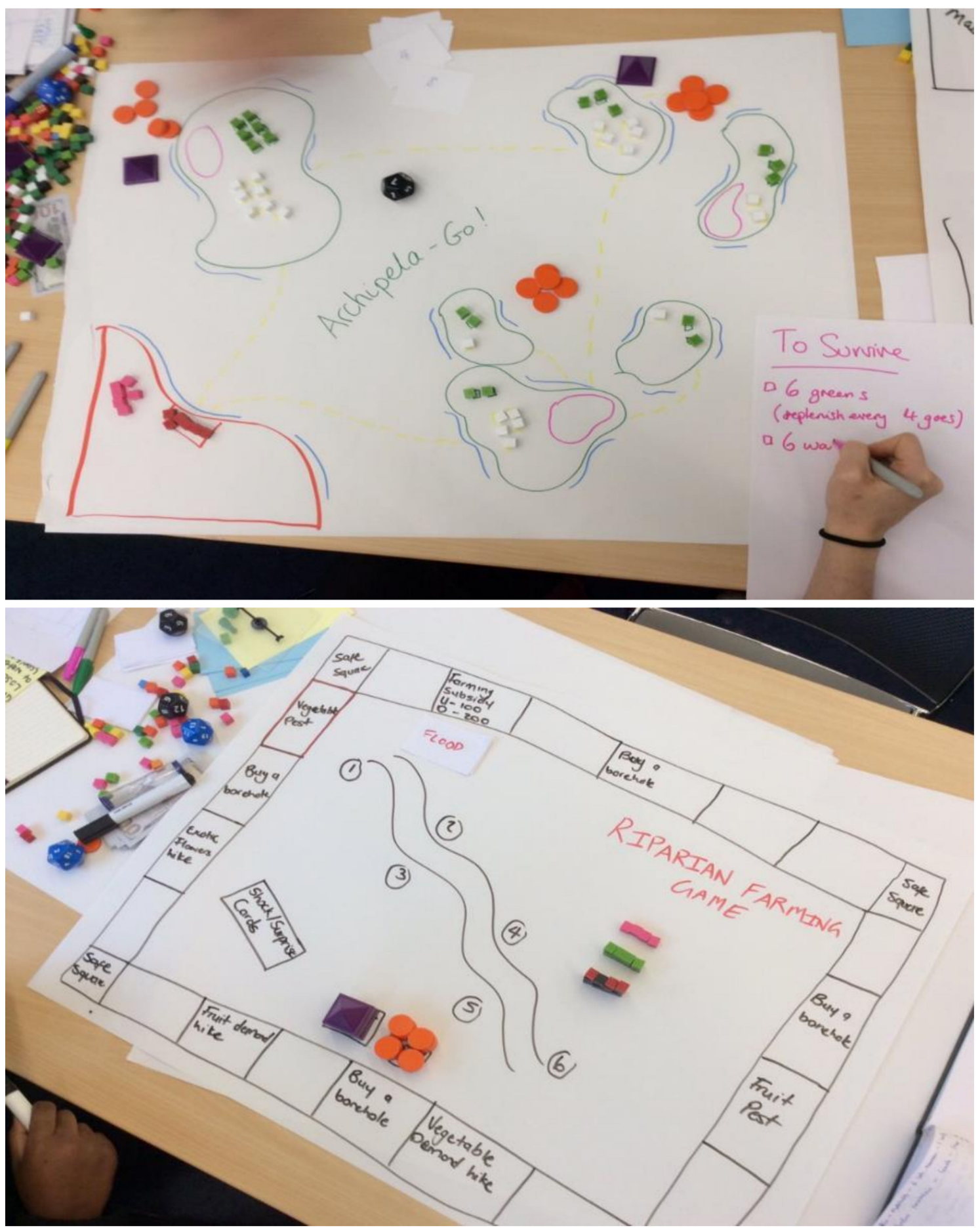

Figure A6. Photos of food systems games (Oxford). 


\section{References}

1. Harteveld, C. Triadic Game Design: Balancing Reality, Meaning and Play; Springer: London, UK, 2011.

2. Aubert, H.A.; Bauer, R.; Lienert, J. A Review of Water-Related Serious Games to Specify Use in Environmental Multi-Criteria Decision Analysis. Environ. Model. Softw. 2018, 105, 64-78. [CrossRef]

3. Maren, W.; Stoll-Kleemann, S. Role-Playing Games in Natural Resource Management and Research: Lessons Learned from Theory and Practice. Geogr. J. 2018, 184, 298-309.

4. Rieber, L.P.; Smith, L.; Noah, D. The Value of Serious Play. Educ. Technol. 1998, 38, $29-37$.

5. Thomas, W. Serious Play in Education for Social Justice-A Mixed-Methods Evaluation. J. New Approaches Educ. Res. 2018, 7, 61-69.

6. Senge, P.M. The Fifth Discipline: The Art and Practice of the Learning Organisation; Doubleday: New York, NY, USA, 1990.

7. Kriz, W.C. Creating Effective Learning Environments and Learning Organizations through Gaming Simulation Design. Simul. Gaming 2004, 34, 495-511. [CrossRef]

8. Herrera, H. From Metaphor to Practice: Operationalizing the Analysis of Resilience Using System Dynamics Modelling. Syst. Res. Behav. Sci. 2017, 34, 444-462. [CrossRef]

9. Alison, J.; Brookfield, S. The Serious Use of Play and Metaphor: Legos and Labyrinths. Int. J. Adult Vocat. Educ. Technol. 2013, 4, 1-12.

10. Kafai, Y.B. Playing and Making Games for Learning. Games Cult. 2006, 1, 36-40. [CrossRef]

11. Aubert, A.H.; Medema, W.; Wals, A.E.J. Towards a Framework for Designing and Assessing Game-Based Approaches for Sustainable Water Governance. Water 2019, 11, 869. [CrossRef]

12. Arthur, P.; de Garine-Wichatitsky, M.; Valls-Fox, H.; le Page, C. My Cattle and Your Park: Codesigning a Role-Playing Game with Rural Communities to Promote Multistakeholder Dialogue at the Edge of Protected Areas. Ecol. Soc. 2017, 22, 35.

13. Steve, C.; Walker, B.; Anderies, J.M.; Abel, N. From Metaphor to Measurement: Resilience of What to What? Ecosystems 2001, 4, 765-781.

14. Norgaard, R.B. Ecosystem Services: From Eye-Opening Metaphor to Complexity Blinder. Ecol. Econ. 2010, 69, 1219-1227. [CrossRef]

15. Lankford, B.; Watson, D. Metaphor in Natural Resource Gaming: Insights from the River Basin Game. Simul. Gaming 2007, 38, 421-442. [CrossRef]

16. West, M.A. Sparkling Fountains or Stagnant Ponds: An Integrative Model of Creativity and Innovation Implementation in Work Groups. Appl. Psychol. 2002, 51, 355-387. [CrossRef]

17. Sannino, A.; Ellis, V. Activity-Theoretical and Sociocultural Approaches to Learning and Collective Creativity: An Introduction. In Learning and Collective Creativity; Sannino, A., Ellis, V., Eds.; Routledge: New York, NY, USA, 2014; pp. 1-19.

18. Wietske, M.; Furber, A.; Adamowski, J.; Zhou, Q.; Mayer, I. Exploring the Potential Impact of Serious Games on Social Learning and Stakeholder Collaborations for Transboundary Watershed Management of the St. Lawrence River Basin. Water 2016, 8, 175.

19. Joanne, C.; Angarita, H.; Perez, G.A.C.; Vasquez, D. Development and Testing of a River Basin Management Simulation Game for Integrated Management of the Magdalena-Cauca River Basin. Environ. Model. Softw. 2017, 90, 78-88.

20. Jean, S.; Medema, W.; Adamowski, J.; Chew, C.; Delaney, P.; Wals, A. Serious Games as a Catalyst for Boundary Crossing, Collaboration and Knowledge Co-Creation in a Watershed Governance Context. J. Environ. Manag. 2018, 223, 1010-1022. [CrossRef]

21. Kafai, Y.B.; Burke, Q. Constructionist Gaming: Understanding the Benefits of Making Games for Learning. Educ. Psychol. 2015, 50, 313-334. [CrossRef]

22. Roger, E.; Smith, S. From Playing to Designing: Enhancing Educational Experiences with Location-Based Mobile Learning Games. Australas. J. Educ. Technol. 2017, 33, 41-53.

23. Loizos, H.; Jacobs, C.D. Crafting Strategy: The Role of Embodied Metaphors. Long Range Plan. 2008, 41, 309-325.

24. Johan, R.; Victor, B. Towards a New Model of Strategy-Making as Serious Play. Eur. Manag. J. 1999, 17, 348-355. 
25. Hmelo, C.E.; Holton, D.L.; Kolodner, J.L. Designing to Learn About Complex Systems. J. Learn. Sci. 2000, 9 , 247-298. [CrossRef]

26. Holliday, G.; Statler, M.; Flanders, M. Developing Practically Wise Leaders through Serious Play. Psychol. J. Pract. Res. 2007, 59, 126-134. [CrossRef]

27. Matt, S.; Oliver, D. Facilitating Serious Play. In The Oxford Handbook on Organizational Decision-Making; Hodgkinson, G.P., Starbuck, W.H., Eds.; Oxford University Press: Oxford, UK, 2008; pp. 475-494.

28. Hinthorne, L.L.; Schneider, K. Playing with Purpose: Using Serious Play Enhance Participatory Development Communication in Research. Int. J. Commun. 2012, 6, 2801-2824.

29. Klaus-Peter, S.; Geithner, S.; Woelfel, C.; Krzywinski, J. Toolkit-Based Modelling and Serious Play as Means to Foster Creativity in Innovation Processes. Creat. Innov. Manag. 2015, 24, 323-340.

30. Swyers, E.L. Investigating Learner Beliefs Using the Lego Serious Play Method. Master's Thesis, University of Waterlooand and the Universität Mannheim, Waterloo, ON, Canada, Mannheim, Germany, 2017.

31. Irene, G.; Flores, A. Using Student-Made Games to Learn Mathematics. Primus 2010, 20, 405-417.

32. Jon, C.K.; Rule, A.C.; Forsyth, B.R. Mathematical Game Creation and Play Assists Students in Practicing Newly-Learned Challenging Concepts. Creat. Educ. 2015, 6, 1484-1495.

33. Joli, S. A Game Design Assignment: Learning About Social Class Inequality. Horizon 2016, 24, $121-125$.

34. D'Aquino, P.; Le Page, C.; Bousquet, F.; Bah, A. Using Self-Designed Role-Playing Games and a Multi-Agent System to Empower a Local Decision-Making Process for Land Use Management: The Selfcormas Experiment in Senegal. J. Artif. Soc. Soc. Simul. 2003, 6, 2-5.

35. Arnab, S.; Berta, R.; Earp, J.; de Freitas, S.; Popescu, M.; Romero, M.; Stanescu, I.; Usart, M. Framing the Adoption of Serious Games in Formal Education. Electron. J. e-Learn. 2012, 10, 159-171.

36. Cheok, A.D.; Hwee, G.K.; Wei, L.; Teo, J.; Lee, T.S.; Farbiz, F.; Ping, L.S. Connecting the Real World and Virtual World through Gaming; Springer: Boston, MA, USA, 2004.

37. Proulx, J.N.; Romero, M.; Arnab, S. Learning Mechanics and Game Mechanics under the Perspective of Self-Determination Theory to Foster Motivation in Digital Game Based Learning. Simul. Gaming 2016, 48, 81-977. [CrossRef]

38. Van Maele, D.; Van Houtte, M.; Forsyth, P.B. Introduction: Trust as a Matter of Equity and Excellence in Education. In Trust and School Life; Springer: Berlin/Heidelberg, Germany, 2014; pp. 1-33.

39. Jacobs, C.D.; Matt, S. Toward a Technology of Foolishness: Developing Scenarios through Serious Play. Int. Stud. Manag. Organ. 2006, 36, 77-92. [CrossRef]

40. March, J.G. The Technology of Foolishness. In Ambiguity and Choice in Organizations; March, J.G., Olsen, J.P., Eds.; Universitetsforlaget: Bergen, Norway, 1979; pp. 69-81.

41. Marsh, T. Slow Serious Games, Interactions and Play: Designing for Positive and Serious Experience and Reflection. Entertain. Comput. 2016, 14, 45-53. [CrossRef]

42. Prensky, M. Students as Designers and Creators of Educational Computer Games: Who Else? Br. J. Educ. Technol. 2008, 39, 1004-1019. [CrossRef]

43. Andrea, V.; Marchetti, E. Make and Play: Card Games as Tangible and Playable Knowledge Representation Boundary Objects. In Proceedings of the 2015 IEEE 15th International Conference on Advanced Learning Technologies, Hualien, Taiwan, 6-9 July 2015.

(C) 2020 by the authors. Licensee MDPI, Basel, Switzerland. This article is an open access article distributed under the terms and conditions of the Creative Commons Attribution (CC BY) license (http://creativecommons.org/licenses/by/4.0/). 